\title{
"Effect of Segmental Baffles at Different Orientation on the Performances of Single Pass Shell and Tube Heat Exchanger"
}

\author{
Neeraj kumar ${ }^{1}$, Dr. Pradeep kumar Jhinge ${ }^{2}$ \\ ${ }^{1}$ Research Scholar, Department of Mechanical Engineering, Government Engineering College, Jabalpur - \\ 482011, (M.P), India. \\ ${ }^{2}$ Professor, Department of Mechanical Engineering, Government Engineering College, Jabalpur - 482011, \\ (M.P), India.
}

\begin{abstract}
In present work, experimentation of single pass, counter flow shell and tube heat exchanger containing segmental baffles at different orientations has been conducted to calculate some parameters (heat transfer rate and pressure drop) at different Reynolds number in laminar flow. In the present work, an attempt has been made to study the effect of increase in Reynolds number at different angular orientation " $\theta$ " of the baffles. The range of " $\theta$ " vary from $0^{\circ}$ to $45^{\circ}$ (i.e $0^{\circ}, 15^{\circ}, 30^{\circ}$ and $45^{\circ}$ ) and Reynolds number ranges from 500 to 2000 (i.e 500, 1000, 1500 and 2000).

A prototype model of shell and tube type heat exchanger has been fabricated to carry out the experiments. The experiments were performed to determine the effect of baffle orientation on the performance of shell and tube heat exchanger. Water is taken as the working fluid used in both shell and tubes. The objective of the present work is to predict the variation of heat transfer rate, LMTD, heat transfer coefficient, and pressure drop to the shell side with change in range of Reynolds number at different baffle orientations.

Based on the experimental result it has been observed that the angular orientation of baffles and the Reynolds number effects the heat transfer rate and pressure drop in the shell and tube heat exchanger. The heat transfer rate increases up to $30^{\circ}$ angular orientation of the baffles and after that there is a drop in heat transfer rate at $\theta=45^{\circ}$. The pressure drop to the shell sides decreases continuously from $0^{\circ}$ to $45^{\circ}$ which helps in reducing
\end{abstract}

the pumping cost of the shell and tube heat exchanger.

Keywords: Shell and Tube heat Exchanger, Heat Transfer Rate, Heat Transfer Coefficient, Pressure Drop, Baffles.

\section{Introduction}

A heat exchanger is a device built for efficient heat transfer from one medium to another in order to carry and process energy. They are widely used in petroleum refineries, chemical plants, petrochemical plants, natural gas processing, air-conditioning, refrigeration, and automotive applications. The most commonly used type of heat exchanger is the shell and tube heat exchanger. It is essential to mention that a heat exchanger is not only an apparatus for transferring heat from one medium to another, but is at the same time a pressure and/or containment vessel. In addition to heating up or cooling down fluids in just a single phase, shell and tube heat exchangers can be used either to heat a liquid to evaporate (or boil) it or used as condensers to condense a vapor back to a liquid.

To increase the heat transfer rate in shell and tube type heat exchanger the segmental baffles are introduced inside the cover pipe. The flow arrangement is counter flow as it is more efficient than parallel flow arrangement. One of the most important parts in shell and tube heat exchangers are the baffles. Baffles serve mainly two functions: 
- Fixing of the tubes in the proper position during assembly and prevention of tube vibration caused by flow-induced eddies.

- Guidance of the shell-side flow across the tube field, increasing the velocity and the heat transfer coefficient.

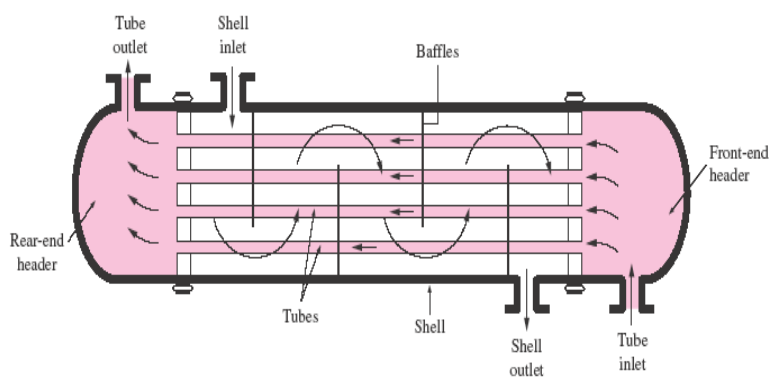

Figure: 1 Different Parts of Shell and Tube Heat Exchanger.

\section{Proposed Work}

- In present work, experimentation of single pass, counter flow shell and tube heat exchanger containing segmental baffles at different orientations has been conducted to calculate some parameters (heat transfer rate and pressure drop) at different Reynolds number in laminar flow.

- A prototype model of shell and tube type heat exchanger has been fabricated to carry out the experiments

- Water is taken as the working fluid used in both shell and tubes.

- The flow arrangement used in analysis is counter flow as it is more efficient than parallel flow arrangement.

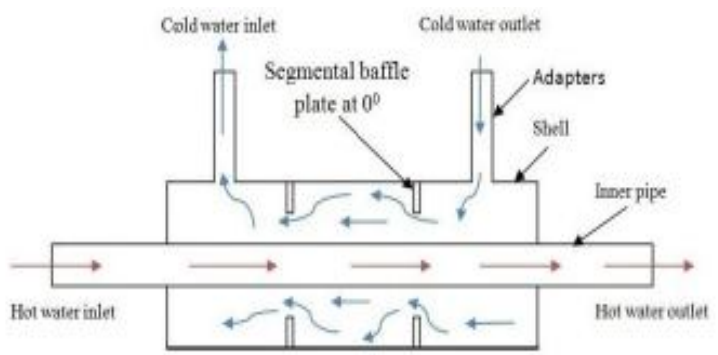

- In the present work, an attempt has been made to study the effect of increase in Reynold number at different angular orientation " $\theta$ " of the baffles. The range of " $\theta$ " vary from $0^{\circ}$ to $45^{\circ}$ (i.e $0^{\circ}, 15^{\circ}, 30^{\circ}$ and $45^{\circ}$ ) and Reynold number ranges from 500 to 2000 (i.e $500,1000,1500$ and 2000).

\section{Components and Specifications Used for Setup}

The components used in the experimental setup of Shell and Tube Heat Exchanger and their specification are tabulated in table:

Table: 1 Components and Specifications used for Setup

\begin{tabular}{|c|c|c|c|}
\hline S. No. & Component Name & Specification & Quantity \\
\hline 1 & Shell outer diameter & $180 \mathrm{~mm}$ & \\
\hline 2 & Shell inner diameter & $170 \mathrm{~mm}$ & \\
\hline 3 & Thickness of shell & $5 \mathrm{~mm}$ & \\
\hline 4 & Tube outer diameter & $19 \mathrm{~mm}$ & \\
\hline 5 & Tube inner diameter & $17 \mathrm{~mm}$ & \\
\hline 6 & Thickness of tube & $1 \mathrm{~mm}$ & \\
\hline 7 & Length of tube & $320 \mathrm{~mm}$ & \\
\hline 8 & Number of tubes & & 10 \\
\hline 9 & Number of baffles & & 4 \\
\hline 10 & Number of pumps & $\begin{array}{l}220 / 240 \mathrm{~V} \mathrm{AC} \\
50 \mathrm{~Hz}, \mathrm{Ph}-1,35 \mathrm{~W}\end{array}$ & 2 \\
\hline 11 & Electronic Regulator & 6 Amp $240 \mathrm{~V}$ AC & 2 \\
\hline \multirow[t]{2}{*}{12} & Electrical water heater & $230 \mathrm{~V} \mathrm{AC} 50 \mathrm{HZ} 1000 \mathrm{~W}$ & 1 \\
\hline & Measuring Devices & & \\
\hline 13 & Digital thermometer & & 1 \\
\hline 14 & U-Tube manometer & & 1 \\
\hline 15 & Beaker & 2 lit. & 1 \\
\hline
\end{tabular}

\section{Experimental Setup}

The different key components of the shell and tube heat exchanger with their measuring devices are shown in Figure: 3.

Figure: 2 Shell \& Tube Heat Exchanger Containing Segmental Baffles at $0^{\circ}$. 


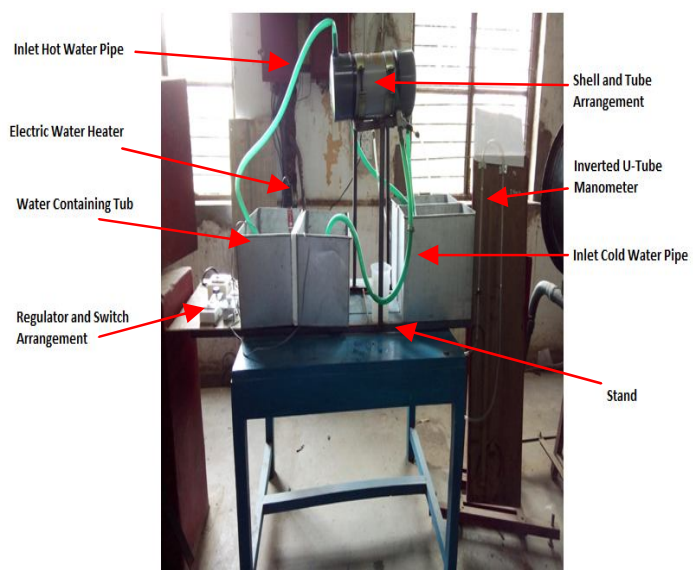

Figure: 3. Experimental Setup Photograph of Shell and Tube Heat Exchanger.

\section{FORMULAE:}

\begin{tabular}{|c|c|c|}
\hline Sr.No. & PARAMETERS & DATA REDUCTION \\
\hline 1. & Total heat transfer rate & $\mathbf{Q}=\mathbf{U A} \mathbf{A} \boldsymbol{\theta}$ \\
\hline 2. & $\begin{array}{l}\text { Logarithmic mean } \\
\text { temperature difference, } \\
\text { LMTD }\end{array}$ & $\theta_{\mathrm{m}}=\frac{\theta_{1}-\theta_{2}}{\ln \left(\frac{\theta_{1}}{\theta_{2}}\right)}$ \\
\hline 3. & $\begin{array}{l}\text { Overall heat transfer } \\
\text { coefficient } \\
\text { (1)Inner surface } \\
\text { (2) Outer surface }\end{array}$ & $\begin{array}{c}U_{i}= \\
=\frac{1}{\frac{1}{h_{i}}+R_{f i}+\frac{r_{i}}{k} \ln \left(\frac{r_{o}}{r_{i}}\right)+\left(\frac{r_{i}}{r_{o}}\right) R_{f o}+\left(\frac{r_{i}}{r_{o}}\right) \frac{1}{h_{o}}} \\
=\frac{U_{0}}{\left(\frac{r_{o}}{r_{i}}\right) \frac{1}{h_{i}}+\left(\frac{r_{o}}{r_{i}}\right) R_{f i}+\left(\frac{r_{o}}{k}\right) \ln \left(\frac{r_{o}}{r_{i}}\right)+R_{f o}+\frac{1}{h_{o}}}\end{array}$ \\
\hline 4. & $\begin{array}{l}\text { Heat transfer } \\
\text { coefficient }\end{array}$ & $h=\frac{m c_{p} \Delta t}{\pi D L \theta_{m}}$ \\
\hline 5. & Reynold number & $\operatorname{Re}=\frac{\rho V D}{\mu}$ \\
\hline 6. & Mass flow rate & $\mathbf{m}=\mathbf{A} \times V \times \boldsymbol{\rho}$ \\
\hline 7. & Pressure drop & $\Delta P=g \times H \times\left(\rho_{h}-\rho_{l}\right)$ \\
\hline
\end{tabular}

Result and Discussion:

In present work, experimentation of single pass, counter flow shell and tube heat exchanger containing segmental baffles at different orientations has been conducted to calculate some parameters (heat transfer rate and pressure drop) at different Reynolds number in laminar flow. In the present work, an attempt has been made to study the effect of increase in Reynolds number at different angular orientation " $\theta$ " of the baffles. The range of " $\theta$ " vary from $0^{\circ}$ to $45^{\circ}$ (i.e. $0^{\circ}, 15^{\circ}, 30^{\circ}$ and $45^{\circ}$ ) and Reynolds number ranges from 500 to 2000 (i.e. 500, 1000, 1500 and 2000).
A prototype model of shell and tube type heat exchanger has been fabricated to carry out the experiments. This experimental setup had been placed on the ground of the heat and mass transfer lab, Department of Mechanical Engineering, Jabalpur Engineering College, Jabalpur (M.P). The experiments were performed to determine the effect of baffle orientation on the performance of shell and tube heat exchanger. Water is taken as the working fluid used in both shell and tubes. The objective of the present work is to predict the variation of heat transfer rate, LMTD, heat transfer coefficient, and pressure drop to the shell side with change in range of Reynolds number at different baffle orientations.

- In the experiment, we have recorded the inlet and outlet temperature of hot and cold fluid at different Reynolds number with different angle of orientation of Baffle plates ( i.e $0^{\circ}, 15^{\circ}, 30^{\circ}$ and $45^{\circ}$ ) one by one.

- With the help of these measuring parameters we have to calculate the variation of heat transfer rate, LMTD, heat transfer coefficient, and pressure drop to the shell sides of the heat exchanger. Mathematical calculations are done in the earlier section.

- From the next pages the no of tables are presented after which the graphs are plotted to see the effect of various parameters with respect to each other.

Tables for Different Baffle Orientations:-

Table: 1 Different Performance Assessment when

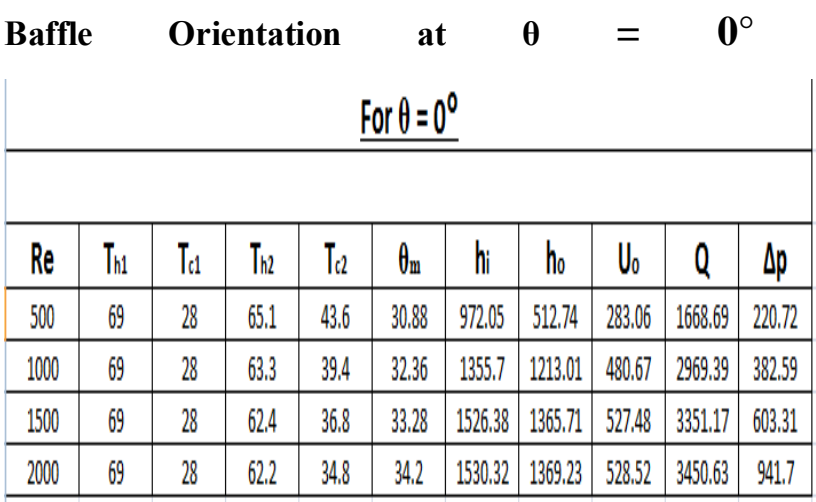


Table: 2 Different Performance Assessment when Baffle Orientation at $\theta=15^{\circ}$

\section{For $\theta=15^{\circ}$}

\begin{tabular}{|c|c|c|c|c|c|c|c|c|c|c|}
\hline & $T_{h 1}$ & Ta & $T_{h 2}$ & $T_{1}$ & $\theta_{\text {m }}$ & $h_{i}$ & $h_{0}$ & $U_{0}$ & $Q$ & ap \\
\hline & 69 & 28 & 64.8 & 4.8 & 30,06 & 1075.53 & 962.18 & 398.27 & 22855.5 & 191.29 \\
\hline & 69 & 28 & 63.1 & 39.8 & 32,15 & 1446.86 & 1267,72 & 497,73 & 3045,31 & JNASO \\
\hline & 69 & 28 & 62.1 & 37,17 & 32.95 & 1611.75 & 1437,38 & 599,32 & 3455,36 & 559.1 \\
\hline & 69 & 28 & 61.9 & 35.1 & 33.9 & 1611.99 & 1422.3 & 550.08 & 35599.88 & \\
\hline
\end{tabular}

Table: 3 Different Performance Assessment when Baffle Orientation at $\boldsymbol{\theta}=\mathbf{3 0}^{\circ}$

\begin{tabular}{|c|c|c|c|c|c|c|c|c|c|c|}
\hline & & & & & & & & & & \\
\hline Re & $T_{h 1}$ & $T_{d}$ & $T_{h}$ & $T_{02}$ & $\theta_{11}$ & $h_{i}$ & ho & $U_{0}$ & l & $\Delta p$ \\
\hline 500 & 69 & 28 & 64.4 & 46.4 & 28.95 & 1222,96 & 1094,23 & 422.53 & 245.7 & 147,15 \\
\hline 1000 & 69 & 28 & 62.9 & 40.2 & 31.75 & 14778.83 & 1333,07 & 514,66 & 3119.4 & 309.01 \\
\hline 1500 & 69 & 28 & 61.5 & 37.97 & 32.24 & 1790,48 & 1597,2 & 594,77 & 3660,62 & 500,31 \\
\hline 2000 & 69 & 28 & 61.4 & 35.6 & 33.4 & 1751.34 & 15660.99 & 585,68 & 3734,36 & 824,04 \\
\hline
\end{tabular}

Table: 4 Different Performance Assessment when Baffle Orientation at $\theta=45^{\circ}$

For $\theta=45^{\circ}$

\begin{tabular}{|c|c|c|c|c|c|c|c|c|c|c|}
\hline & $T_{h 1}$ & $T$ & $T_{\mathrm{h} 2}$ & $T_{a}$ & $\theta_{11}$ & $h_{i}$ & $h_{0}$ & $V_{0}$ & Q & $\Delta p$ \\
\hline & 69 & 28 & 64.6 & 45.6 & 29.5 & 1147,98 & 1027,14 & 420,29 & 23660.89 & \\
\hline & 69 & 28 & 63 & 40 & 31.9 & 1447,65 & 1295,26 & 506.17 & 3022,46 & \\
\hline & 69 & 28 & 61.8 & 37.57 & 32.6 & 16998.88 & 15166,19 & 572,02 & 3559.89 & 426. \\
\hline & 69 & 28 & 61.6 & 55 & 33.6 & 1605.1 & 15166,67 & 571.49 & 3665.69 & 73 \\
\hline
\end{tabular}

Graphs between Different Parameters:-

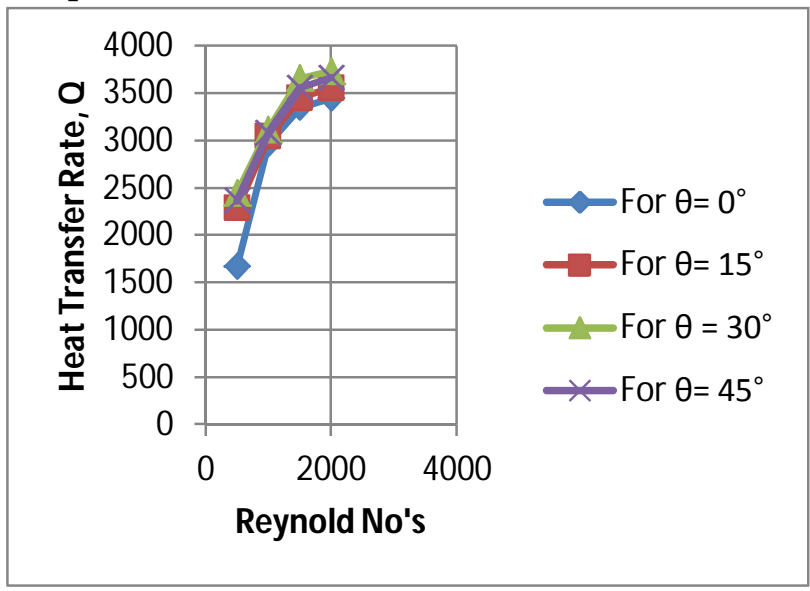

Figure: 4 Performance Assessment of Heat Transfer Rate Vs Reynolds number.

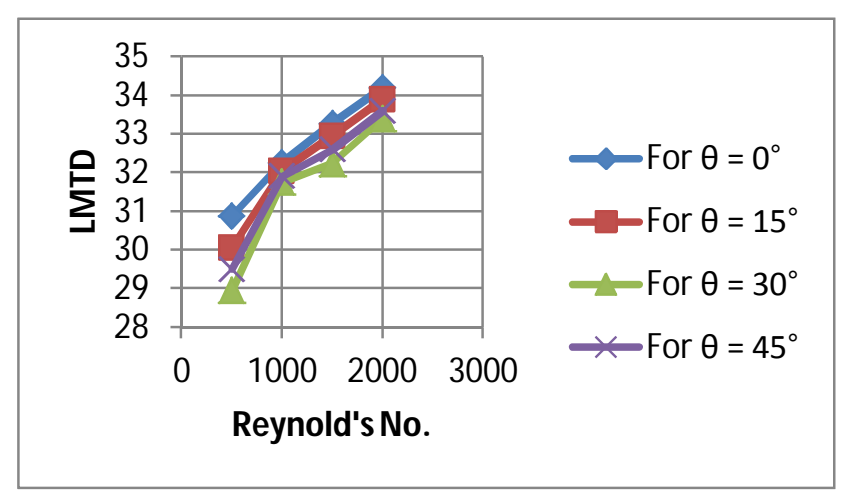

Figure: 5 Performance Assessment of LMTD Vs Reynolds number.

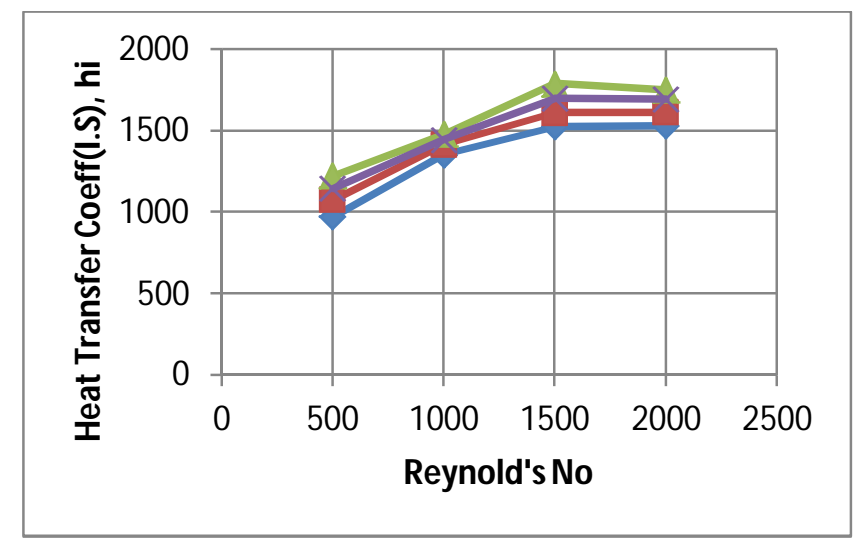

Figure: 6 Performance Assessment of Heat Transfer Coefficient (Inner Side) Vs Reynolds Number. 


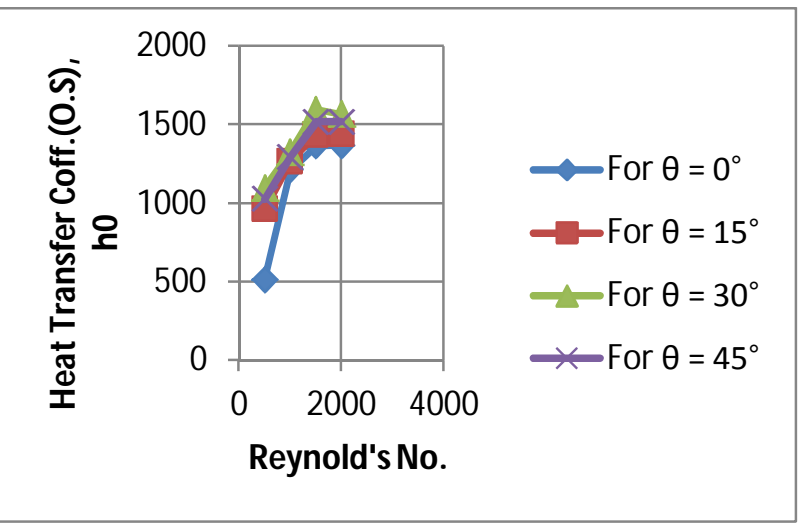

Figure: 7 Performance Assessment of Heat Transfer Coefficient (Outer Side) Vs Reynolds Number.

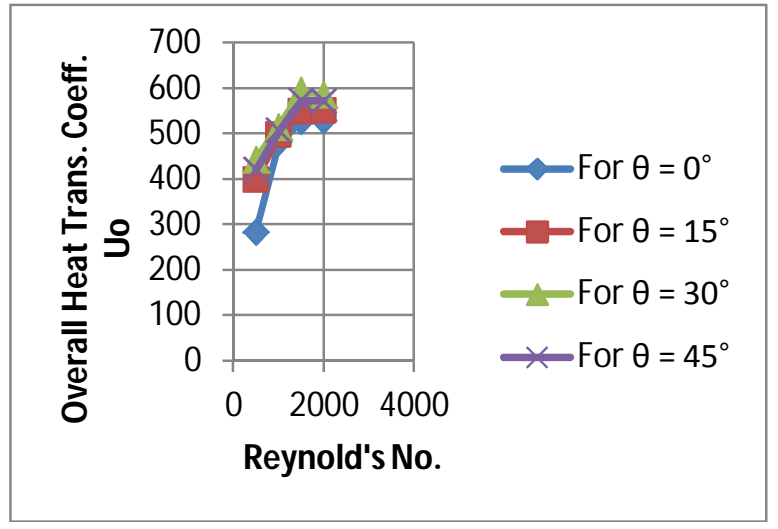

Figure: 8 Performance Assessment of Overall Heat Transfer Coefficient Vs Reynolds Number.

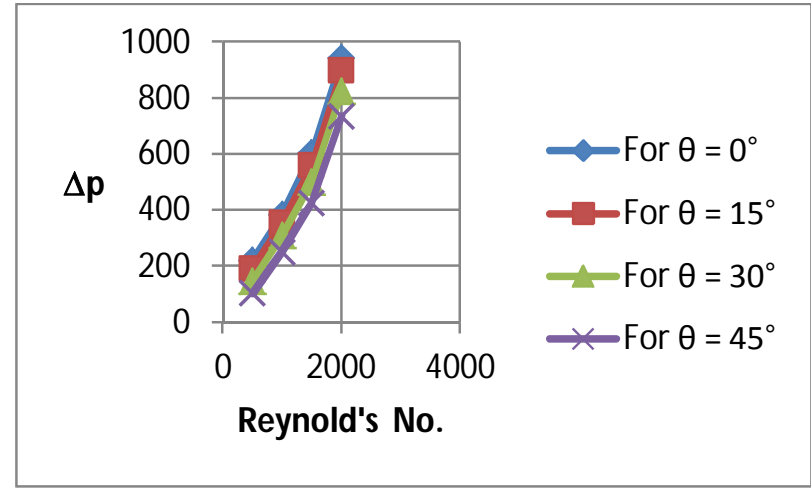

Figure: 9 Performance Assessment of Pressure Drop Vs Reynolds Number.

\section{Conclusion}

In present work, experimentation of single pass, counter flow shell and tube heat exchanger containing segmental baffles at different orientations has been conducted to calculate some parameters (heat transfer rate and pressure drop) at different Reynolds number in laminar flow. In the present work, an attempt has been made to study the effect of increase in Reynolds number at different angular orientation " $\theta$ " of the baffles. The range of " $\theta$ " vary from $0^{\circ}$ to $45^{\circ}$ (i.e $0^{\circ}, 15^{\circ}, 30^{\circ}$ and $45^{\circ}$ ) and Reynolds number ranges from 500 to 2000 (i.e 500, 1000,1500 and 2000.

Based on the experimental result has been observed that the angular orientation of baffles and the Reynolds number effects heat transfer rate and pressure drop in the shell and tube heat exchanger. The heat transfer rate increases up to $30^{\circ}$ angular orientation of the baffles and after that there is a drop in heat transfer rate at $\Theta\left(45^{\circ}\right)$. The pressure drop to the shell sides decreases continuously from $0^{\circ}$ to $45^{\circ}$ which helps in reducing the pumping cost of the shell and tube heat exchanger.

\section{Nomenclature:}

Q Total heat transfer rate (w)

U Overall heat transfer coefficient $\left(\mathrm{w} / \mathrm{m}^{2 \circ} \mathrm{C}\right)$

A $\quad$ Heat transfer area $\left(m^{2}\right)$

$\theta_{m} \quad$ Logarithmic mean temperature difference, LMTD $\left({ }^{\circ} \mathrm{C}\right)$

$\mathrm{H} \quad$ Coefficient of convective heat transfer $\left(\mathrm{w} / \mathrm{m}^{2 \circ} \mathrm{C}\right)$

$D_{o} \quad$ Outer diameter of tube $(\mathrm{m})$

$D_{i} \quad$ Inner diameter of tube (m)

L Length of tube (m)

V Velocity of water $(\mathrm{m} / \mathrm{s})$

M Mass flow rate of water $(\mathrm{kg} / \mathrm{s})$

P Density of water $\left(\mathrm{kg} / \mathrm{m}^{3}\right)$

$\mu \quad$ Dynamic viscosity of water $\left(\mathrm{n}-\mathrm{s} / \mathrm{m}^{2}\right)$ 
$C_{P} \quad$ Specific heat of water $\left(\mathrm{j} / \mathrm{kg}^{\circ} \mathrm{C}\right)$

$R_{f} \quad$ Fouling factor $\left(m^{2 \circ} \mathrm{C} / \mathrm{w}\right)$

$\mathrm{T} \quad$ Temperature of water $\left({ }^{\circ} \mathrm{C}\right)$

K Thermal conductivity $\left(\mathrm{w} / \mathrm{m}^{\circ} \mathrm{C}\right)$

$\Delta P \quad$ Pressure drop $\left(\mathrm{n} / \mathrm{m}^{2}\right)$

G Acceleration due to gravity $\left(\mathrm{m} / \mathrm{s}^{2}\right)$

$\mathrm{H} \quad$ Difference in fluid(turpentine oil) level (m)

$\rho_{h} \quad$ Density of heavy fluid, water $\left(\mathrm{kg} / \mathrm{m}^{3}\right)$

$\rho_{l} \quad$ Density of light fluid, turpentine oil $\left(\mathrm{kg} / \mathrm{m}^{3}\right)$

\section{References:}

1. Amarjit Singh, and Satbir Sehgal, "Computational analysis of the effect of segmental baffle orientation in shell and tube heat exchanger", International Journal of Mechanical Science and Civil Engineering, Vol. 2, Issue 2, pp.10-14, 2013.
2. H. Lia, V. Kottkeb, aJiangxi-OAI Joint Institute, Nanchang 330047, People's Republic of China bInstitute of Food Technology, Department of Food Process Engineering, Hohenheim University, 70599 Stuttgart, GermanyReceived 15 April 1998; received in revised form 16 November 1998.

3. K.Mohammadi, Wolfgang Heidemann and Hans Muller-Steinhagen, "Numerical investigation of the effect of baffle orientation on heat transfer and pressure drop in a shell and tube heat exchanger with leakage flows", Heat Transfer Engineering, Vol. 30, Issue 14, pp.1123-1135, 2009.

4. N. Ghorbani, H. Taherian, M. Gorji-Bandpy, Designing Shell-and-Coil Mixed Convection Heat Exchangers, Proceedings of 2008 ASME Summer Heat Transfer Conference, Jacksonville, Florida, August 2008.

5. Qiuwang Wang, Qiuyang Chen, Guidong Chen, Min Zeng, "Numerical investigation on combined multiple shell-pass shell-and-tube heatexchanger with continuous helical baffles", International Journal of Heat and Mass Transfer 52 (2009) 1214-1222.

6. Sunilkumar Shinde, Mustansir Hatim Pancha / International Journal of Engineering Research and Applications (IJERA) ISSN: 2248-9622, Vol. 2, Issue4, July-August 2012, pp.2264-2271. 